low rate of adverse transfusion reactions during the 18 months analyzed. The most frequent adverse reaction was shortness of breath.

Disclosure of Interest: None declared

DOI: 10.1136/annrheumdis-2017-eular.6470

\section{FRI0238 EFFECT OF BASELINE ANTI-CYCLIC CITRULLINATED PEPTIDE 3 ANTIBODY TITRE ON LONG-TERM DRUG SURVIVAL OF SUBCUTANEOUS ABATACEPT IN RHEUMATOID ARTHRITIS: A PROSPECTIVE COHORT STUDY}

J.C. Sarmiento-Monroy $^{1,2}$, N. Molano-González ${ }^{2}$, M. Rodríguez-Jiménez ${ }^{2}$, R.D. Mantilla ${ }^{1,2} \cdot{ }^{1}$ Rheumatology, Center of Dermatology and Rheumatology (FUNINDERMA); ${ }^{2}$ Center for Autoimmune Diseases Research (CREA), Universidad del Rosario, Bogotá, Colombia

Background: Clinical response to biologics varies widely between individuals with rheumatoid arthritis (RA). To date, there are few, and in some cases, conflicting results in the personalized approach of patients with RA treated with abatacept. Only the seropositive subphenotype (anti-cyclic citrullinated peptide, CCP) was validated in several populations, including a real-life registry (ORA) [1], and non-inferiority trial (AMPLE) [2]

Objectives: To assess whether baseline anti-CCP3 antibody status and concentration correlated with drug survival of subcutaneous (SC) abatacept among patients with $\mathrm{RA}$ in a real-world setting.

Methods: This was a prospective study in which well-characterized patients with RA (by 1987 ACR criteria) were included from April 2014 to December 2016. Patients were evaluated at a single rheumatology outpatient center in Bogotá, Colombia. Baseline anti-CCP3 antibody status (positive/negative) and concentration were determined using an anti-CCP3 lgG ELISA (INOVA Diagnostics). Patients with a baseline anti-CCP3 IgG concentration of $\geq 20 U$ were considered to be positive and were further divided into equal quartiles according to concentration [Q1-Q4 (highest concentration)]. The Cox proportional hazards regression model was used to test if there were any differences in drug survival curves according to baseline anti-CCP3 antibody status and concentration. The test was performed by the coxph function of the "survival" $R$ package [3].

Results: A total of 129 patients were included. Baseline characteristics: female gender $86 \%$, mean age $52 \pm 13$ years, median disease duration 10 (IQR 11) years, and erosions $35 \%$. Treatment background was as follows: biologic-naïve $(n=54)$, switched from IV to SC abatacept administration $(n=24)$, and inadequate response to at least 1 biologic disease-modifying antirheumatic drug $(n=51)$. Forty-three patients (33\%) discontinued treatment. The most frequent reasons for drug suspension were loss of efficacy. Rheumatoid Factor and anti-CCP3 was positive in $94 \%$, and $89 \%$, respectively. Median titre of anti-CCP3 was $248 \mathrm{U}$ (IQR 352), and number of patients in each quartile group were Q1 $(22-122)=21$; Q2 $(123-248)=20 ;$ Q3 $(249-475)=19 ;$ Q4 $(476-1544)=19$. According to Cox proportional hazards regression model (Fig.1), there were significant differences between survival curves for Q1 (HR 0.1; 0.02-0.60 95\% IC; $\mathrm{p}=0.011$ ), Q2 (HR $0.2 ; 0.06-0.9495 \% \mathrm{IC} ; \mathrm{p}=0.041$ ), and Q3 (HR 0.2; $0.04-0.8595 \% \mathrm{IC} ; \mathrm{p}=0.030$ ), compared to negative group at month 32

Figure 1. Subcutaneous abatacept survival by anti-CCP3 antibody status.

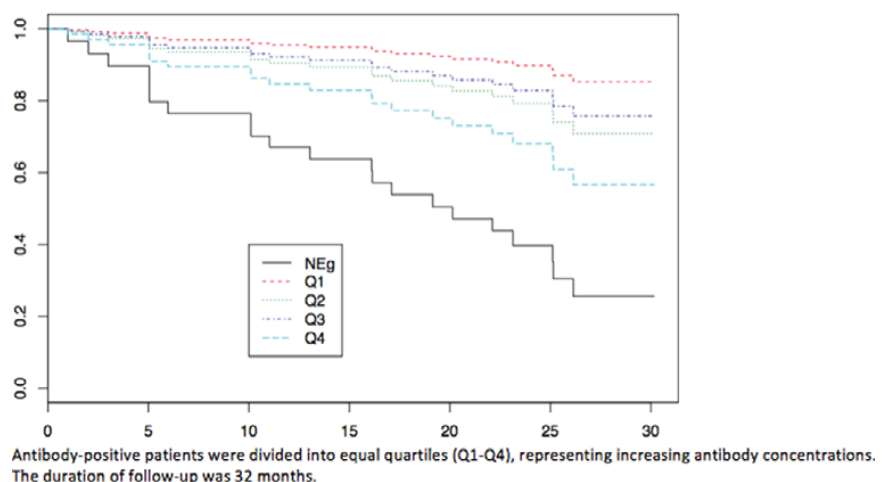

The duration of follow-up was 32 months.

Conclusions: Baseline anti-CCP3 positivity was associated with a better response for SC abatacept in a real-world setting. Patients with lowest baseline anti-CCP3 antibody concentrations had better drug survival than patients with higher concentrations. Our results highlight the importance of identification of factors associated with response to biologics in order to optimize treatment and reduce costs.

References:

[1] Sokolove J, et al. Ann Rheum Dis. 2016;75(4):709-14

[2] Gottenberg JE, et al. Ann Rheum Dis. 2012;71(11):1815-9.

[3] Therneau,T, Grambsch P. Modeling Survival Data: Extending the Cox Model. Springer-Verlag, 2000

Disclosure of Interest: None declared

DOI: 10.1136/annrheumdis-2017-eular.6682

\section{FRI0239 RESULTS OF A PHASE 2B STUDY OF VOBARILIZUMAB, AN ANTI-INTERLEUKIN-6 RECEPTOR NANOBODY, AS MONOTHERAPY IN PATIENTS WITH MODERATE TO SEVERE RHEUMATOID ARTHRITIS}

T. Dörner ${ }^{1}$, M. Weinblatt ${ }^{2}$, K. Van Beneden ${ }^{3}$, E.J. Dombrecht ${ }^{3}$, K. De Beuf ${ }^{3}$, P. Schoen ${ }^{3}$, R.K. Zeldin ${ }^{3} .{ }^{1}$ Rheumatology and Clinical Immunology, Charité University Hospitals, Berlin, Germany; ${ }^{2}$ Division of Rheumatology, Immunology and Allergy, Brigham and Women's Hospital, Boston, United States; ${ }^{3}$ Ablynx NV, Zwijnaarde, Belgium

Background: Vobarilizumab is a Nanobody ${ }^{\circledR}$ consisting of an anti-IL6 receptor domain and an anti-human serum albumin domain in development for treatment of RA.

Objectives: To assess the efficacy and safety of several dose regimens of vobarilizumab monotherapy administered subcutaneously to patients with active RA.

Methods: Patients with active RA who were intolerant to methotrexate (MTX) or for whom continued MTX treatment was inappropriate were randomized in a $1: 1: 1: 1$ ratio to 1 of the 3 blinded dose groups of vobarilizumab or to open-label tocilizumab (TCZ), all of which were given subcutaneously. Efficacy was evaluated descriptively at Week 12 using a number of widely accepted clinical endpoints. Adverse events and routine safety parameters including laboratory assessments were recorded. TCZ administered weekly or biweekly according to local labeling was included to obtain parallel descriptive information.

Results: The study enrolled 251 patients in Europe, Latin America and the United States. Baseline demographics and disease characteristics were well balanced across groups with mean DAS28 ${ }_{\mathrm{CRP}}$ between 5.9 and 6.2 .

\begin{tabular}{|c|c|c|c|c|}
\hline $\begin{array}{l}\text { Week } 12 \\
\text { (\% of patients) }\end{array}$ & $\begin{array}{c}\text { Vobarilizumab } \\
150 \mathrm{mg} q 4 \mathrm{w} \\
(\mathrm{N}=62)\end{array}$ & $\begin{array}{c}\text { Vobarilizumab } \\
150 \mathrm{mg} \text { q2w } \\
(\mathrm{N}=62)\end{array}$ & $\begin{array}{c}\text { Vobarilizumab }(\mathrm{N}=63) \\
225 \mathrm{mg} \mathrm{q} 2 \mathrm{w} \\
(\mathrm{N}=63)\end{array}$ & $\begin{array}{c}\text { Tocilizumab } \\
\text { 162mg q1w }(\mathrm{N}=60) \\
\text { q2w }(\mathrm{N}=4)\end{array}$ \\
\hline ACR20 & 73 & 77 & 81 & 78 \\
\hline ACR50 & 44 & 37 & 49 & 45 \\
\hline ACR70 & 16 & 24 & 21 & 23 \\
\hline \multicolumn{5}{|l|}{ HAQ-DI score } \\
\hline decrease $\geq 0.25$ & 65 & 68 & 71 & 72 \\
\hline DAS28 $8_{\mathrm{ESR}}<2.6$ & 34 & 21 & 40 & 25 \\
\hline DAS28 ${ }_{\text {CRP }}<2.6$ & 26 & 27 & 41 & 27 \\
\hline SDAI remission & 8 & 5 & 8 & 11 \\
\hline CDAI remission & 10 & 5 & 6 & 9 \\
\hline
\end{tabular}

At Week $12,73 \%$ to $81 \%$ of the patients assigned to one of the vobarilizumab groups achieved an ACR20 response, while ACR50 and ACR70 response rates between $37-49 \%$ and $16-24 \%$, respectively, were observed (see table). At the end of the 12-week treatment period, clinically meaningful improvement in HAQ-DI scores and remission based on DAS28 $8_{C R P}$ and DAS28 $8_{\text {ESR }}$ was observed in a substantial number of patients treated with vobarilizumab, either $q 4 \mathrm{w}$ or biweekly. Between $5 \%$ and $10 \%$ of the patients achieved remission defined by the more stringent CDAI or SDAl criteria. In total, $94 \%$ of patients randomized to open-label TCZ received drug weekly. In spite of this disparity in dosing frequency similar efficacy results were obtained in the vobarilizumab and TCZ groups.

One vobarilizumab treated patient $(225 \mathrm{mg}$ q2w treatment group, $1.6 \%)$ experienced a SAE during the treatment period as did 2 patients in the TCZ group $(3.1 \%)$. Frequencies of treatment-emergent adverse events were similar across the groups. Of the vobarilizumab treated patients, $2.1 \%$ discontinued study drug due to TEAEs compared with $6 \%$ in the TCZ group. One case of severe hypersensitivity, not considered serious, was reported in the $225 \mathrm{mg}$ q2w treatment group. Liver function abnormalities were infrequent across all study groups. Grade 3 neutrophil toxicities were less commonly observed with vobarilizumab $(1.1 \%)$ than with TCZ (4.3\%).

Conclusions: In patients with active RA, treatment with vobarilizumab monotherapy had a positive impact on disease activity with no unexpected safety findings. Disclosure of Interest: T. Dörner Consultant for: Ablynx, M. Weinblatt Consultant for: Ablynx, K. Van Beneden Employee of: Ablynx, E. Dombrecht Employee of: Ablynx, K. De Beuf Employee of: Ablynx, P. Schoen Employee of: Ablynx, R. Zeldin Employee of: Ablynx

DOI: 10.1136/annrheumdis-2017-eular.3746

\section{FRI0240 RHEUMATOID ARTHRITIS (RA) IMPACT FOLLOWING TREATMENT WITH SARILUMAB: PATIENT REPORTED OUTCOMES USING THE RAID SCALE FROM TWO RANDOMIZED PHASE III TRIALS}

L. Gossec ${ }^{1}$, V. Strand ${ }^{2}$, C. Proudfoot ${ }^{3}$, C. Chen ${ }^{4}$, S. Guillonneau ${ }^{5}$, T. Kimura ${ }^{4}$ H. van Hoogstraten ${ }^{6}$, E. Mangan ${ }^{4}$, M. Reaney ${ }^{3} .{ }^{1}$ Université Pierre et Marie

Curie and Hôpital Pitié-Salpêtrière, Paris, France; ${ }^{2}$ Stanford University, Palo Alto, United States; ${ }^{3}$ Sanofi, Guildford, United Kingdom; ${ }^{4}$ Regeneron

Pharmaceuticals, Inc, Tarrytown, United States; ${ }^{5}$ Sanofi, Paris, France; ${ }^{6}$ Sanofi, Bridgewater, United States

Background: Patients with RA experience a variety of signs and symptoms and report significant physical and psychological impairment. The RA Impact of Disease (RAID) scale is a disease-specific measure of the impact of RA on patients' lives. RAID was assessed in two Phase 3 randomized trials of sarilumab, 
a human monoclonal antibody directed against the IL- 6 receptor- $\alpha$ (TARGET [NCT01709578]; MONARCH [NCT02332590]).

Objectives: To evaluate patient-perceived impact of sarilumab on RA using the RAID scale vs either placebo + conventional synthetic disease-modifying anti-rheumatic drugs (csDMARDs) or adalimumab.

Methods: TARGET assessed sarilumab $150 \mathrm{mg}$ and $200 \mathrm{mg}$ added to csDMARDs vs placebo in patients with RA intolerant of or not responding to anti-TNF therapy. MONARCH assessed sarilumab $200 \mathrm{mg}$ monotherapy vs adalimumab $40 \mathrm{mg}$ monotherapy in patients with RA either intolerant of, inadequate responders to, or considered inappropriate candidates for continued treatment with methotrexate. Treatments were administered subcutaneously every 2 weeks. RAID has 7 single-item domains, each rated by patients on an 11-point numeric rating scale from 0 (absence) to 10 (extreme). A total score from 0 to 10 (with lower scores indicative of less impact of disease) is calculated by weighting responses for each item based on patient assessment of the relative importance of the item. RAID was assessed at baseline (BL), Weeks 12 and 24. Least square mean (LSM) changes from BL in total score (Weeks 12 and 24) and domains (Week 24 only) were analysed with a mixed model for repeated measures, including treatment, region, visit, and treatment-by-visit interaction (and prior csDMARD therapy in TARGET) as fixed effects and BL as a covariate. RAID was tested outside of trial hierarchy and statistical significance is not claimed; nominal p-values are provided. Post-hoc categorical change analyses were conducted to identify "responders" in the total score (improvements $\geq$ minimum clinically important difference from BL to Week 24 [absolute change of 3 or relative change of $50 \%$ in total score]). Patients discontinuing therapy/requiring rescue medication prior to endpoint were classified as non-responders.

Results: Sarilumab was superior (nominal $\mathrm{p}<0.05$ ) to placebo (TARGET) and adalimumab (MONARCH) at Weeks 12 and 24 for RAID total score (Table). There was a greater proportion of responders in both sarilumab dose groups vs placebo at both time points (TARGET) and in sarilumab $200 \mathrm{mg}$ vs adalimumab at Week 24 (MONARCH). The effect of sarilumab was consistent across all 7 individual RAID domains (nominal $p<0.05$ ) at Week 24, except for sleep difficulties vs placebo in TARGET. Effects of placebo were highest on pain and effects of sarilumab were lowest on emotional well-being (TARGET) and coping (MONARCH)

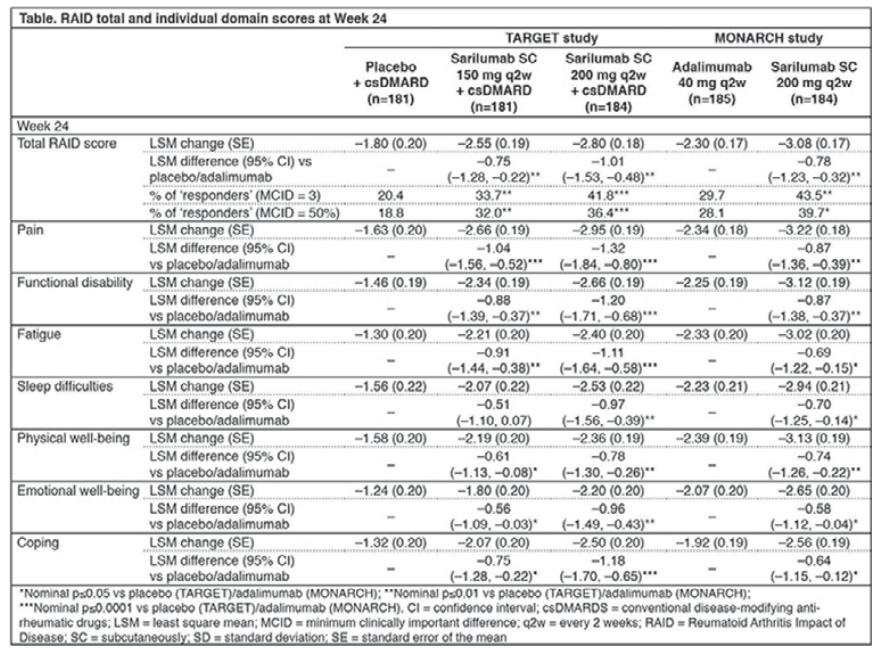

Conclusions: Assessed using RAID, sarilumab either with csDMARDs or as monotherapy reduced the impact of RA on patients' lives to a greater extent than placebo+csDMARDs or adalimumab monotherapy, with benefits shown on total RAID and all 7 individual domain scores.

Acknowledgements: This study was sponsored by Sanofi and Regeneron Pharmaceuticals, Inc.

Disclosure of Interest: L. Gossec Consultant for: Abbvie, Celgene, Janssen, Lilly, Novartis, MSD, Roche, and UCB, V. Strand Consultant for: AbbVie, Amgen, AstraZeneca, Biogen, BMS, Celltrion, CORRONA, Crescendo, Genentech/Roche, GSK, Janssen, Eli Lilly, Novartis, Pfizer, Regeneron Pharmaceuticals, Sandoz, Sanofi, and UCB, C. Proudfoot Shareholder of: Sanofi, Employee of: Sanofi, C. Chen Shareholder of: Regeneron Pharmaceuticals, Inc, Employee of: Regeneron Pharmaceuticals, Inc, S. Guillonneau Shareholder of: Sanofi, Employee of: Sanofi, T. Kimura Shareholder of: Regeneron Pharmaceuticals, Inc, Employee of: Regeneron Pharmaceuticals, Inc, H. van Hoogstraten Shareholder of: Sanofi, Employee of: Sanofi, E. Mangan Shareholder of: Regeneron Pharmaceuticals, Inc, Employee of: Regeneron Pharmaceuticals, Inc, M. Reaney Shareholder of: Sanofi, Employee of: Sanofi DOI: 10.1136/annrheumdis-2017-eular.3448

\section{FRI0241 THE EFFECT OF ABATACEPT ON CYTOKINE PROFILE IN PATIENTS WITH RHEUMATOID ARTHRITIS}

M.A. Borisova, G.V. Lukina, Y. Sigidin, E.L. Luchihina, D.E. Karateev, A. Novikov, E. Alexandrova, E. Aronova, S. Glukhova, E. Nasonov. Nasonova Reserch Institute of Rheumatology, MOSCOW, RUSSIA, Moscow, Russian Federation

Background: Pathological activation of T-cells with the overproduction of proinflammatory cytokines is playing a major role in the pathogenesis of rheumathoid arthritis (RA). The influence of the selective co-stimulation modulator abatacept (ABA) on the dynamics of cytokine profile in patients with RA is not fully understood.

Objectives: To assess the changes in cytokine profile in patients treated with ABA.

Methods: 44 patients with RA and an inadequate response to synthetic DMARDs or biologics were enrolled in the study. Most of them were middle aged females (46,9 $\pm 13,9$ years) with median RA duration 2 years $(1,4-3)$, high disease activity (DAS28 $=5,2 \pm 0,8)$, RF-positive $(80 \%)$ and ACPA-positive (79,5\%). 16 healthy individuals were included in the study as control. The serum levels of IL-1, IL-6, IL-17, TNF- $\alpha$, VEGF, IP-10 (pg/ml) were measured by ELISA immunoassay, YKL-40 by MicroVue immunoassay at baseline and 24 weeks. Disease activity was measured by DAS28, results were assessed every 12 weeks by EULAR criteria. ABA was administered intravenously every 4 weeks.

Results: Levels of IL-6 $(2.4(1,1-6,4)$ vs $0.7(0,62-1,0), p=0,0002)$, YKL-40 (97 $(68,4-97,9)$ vs. $64(52,4-107,5), \mathrm{p}=0,03), \mathrm{IP}-10(21(12,9-49,8)$ vs $14(9,2-15,2)$, $p=0,005$ ) were significantly higher in patients with $R A$ compared to control. $A B A$ significant reduced disease activity already after 12 weeks of therapy $(p<0,05)$. After 24 weeks of ABA therapy good and moderate response by EULAR criteria was achieved in $86 \%$, low disease activity by DAS28 in $52 \%$. By the 6 -th month ABA significant decreased levels of IL-6 $(1,29(0,9-2,2, p=0,0006)$, IP-10 (14 $(7,5-28), p=0.007)$ as well as MMP3: before 30.1 (13-82), after 24 weeks 10 (7.4-55), $\mathrm{p}=0.0003$ and RF: before 218 (9.6-187), after 24 weeks 159 (9.7-155), $\mathrm{p}=0.02$. Lowering of the IL-6 $(r=0,5)$ and IP-10 $(r=0,32)$ levels were significantly $(p<0.05)$ associated with a decrease of DAS28.

Conclusions: ABA therapy leads to a significant reduction in serum levels of IL-6, IP-10, MMP3 and RF. The serum levels of IL-6 and IP-10 correlate with decrease activity of RA.

Disclosure of Interest: None declared

DOI: 10.1136/annrheumdis-2017-eular.6540

\section{FRI0242 ASSOCIATION BETWEEN CLINICAL AND RADIOGRAPHIC RESPONSES, AND PHYSICAL FUNCTION IN A PHASE 3 STUDY OF SARILUMAB PLUS METHOTREXATE IN PATIENTS WITH ACTIVE, MODERATE-TO-SEVERE RHEUMATOID ARTHRITIS}

M.C. Genovese ${ }^{1}$, H. van Hoogstraten ${ }^{2}$, W. Kampman ${ }^{3}$, S. Jayawardena ${ }^{2}$,

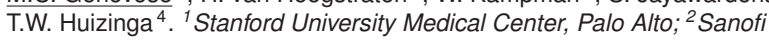
Genzyme, Bridgewater; ${ }^{3}$ Regeneron Pharmaceuticals, Inc., Tarrytown, United States; ${ }^{4}$ Leiden University Medical Centre, Leiden, Netherlands

Background: In MOBILITY (NCT01061736), SC sarilumab (150 or 200 mg q2w) + MTX demonstrated efficacy in adults with RA and inadequate response to MTX. The most common TEAEs were infections, neutropenia, injection site reactions, and increased transaminases.

Objectives: To examine association between clinical response and radiographic progression and functional response (HAQ-DI) in MOBILITY.

Methods: In this post hoc analysis, associations between HAQ-DI and clinical efficacy categories (CDAI, DAS28-CRP, SDAl, and Boolean-based ACR/EULAR remission) were tested at wk 16. Trend for change from baseline (BL) in HAQ-DI across response categories was assessed using the Jonckheere-Terpstra test

Results: Regardless of definition, percentage achieving remission (CDAI $\leq 2.8$, DAS28-CRP $<2.6$, SDAl $<3.3$ ) or no $x$-ray progression was higher with sarilumab vs $\mathrm{Pbo}(P<0.05)$. Overall, there was a significant trend between magnitude of clinical response at wk 16 and improvement in physical function (Table). This trend was also observed for radiographic progression (mTSS change from $\mathrm{BL}$ ),

\begin{tabular}{|c|c|c|c|c|c|c|c|c|}
\hline & \multicolumn{2}{|c|}{$\begin{array}{c}\mathrm{Pbo}+\mathrm{MTX} \\
\mathrm{N}=398\end{array}$} & \multicolumn{2}{|c|}{$\begin{array}{c}\text { Sarilumab } \\
150 \underset{\mathrm{mg}}{\mathrm{mg} 2 w}+\mathrm{MTX} \\
\mathrm{N}=400\end{array}$} & \multicolumn{2}{|c|}{$\begin{array}{c}\text { Sarilumab } \\
200 \underset{\mathrm{mg} q 2 w}{\mathrm{~N}=399}+\mathrm{MTX}\end{array}$} & \multicolumn{2}{|c|}{$\begin{array}{c}\text { All patients* } \\
\mathrm{N}=1197\end{array}$} \\
\hline & $n(\%)$ & mean (SD) & n (\%) & mean (SD) & $n(\%)$ & mean (SD) & $n(\%)$ & mean (SD) \\
\hline \multicolumn{9}{|l|}{ CDAI } \\
\hline$\leq 2.8$ & $13(3)$ & $-0.7(0.5)$ & $25(7)^{\dagger}$ & $-0.8(0.6)$ & $40(11)^{1}$ & $-1.1(0.7)$ & $78(7)$ & $-0.9(0.7)$ \\
\hline$>2.8-\leq 10$ & $47(12)$ & $-0.8(0.8)$ & $92(23)$ & $-0.7(0.6)$ & $105(26)$ & $-0.8(0.6)$ & $244(20)$ & $-0.7(0.6)$ \\
\hline$>10$ & $315(79)$ & $.0 .2(0.5)$ & $242(61)$ & $-0.5(0.5)$ & $218(55)$ & $.0 .4(0.5)$ & $775(65)$ & $-0.3(0.5)$ \\
\hline \multicolumn{9}{|l|}{ DAS28-CRP } \\
\hline$<2.6$ & $22(6)$ & $-0.7(0.6)$ & $88(25)^{1}$ & $-0.8(0.6)$ & $109(31)^{1}$ & $-0.9(0.7)$ & $219(18)$ & $-0.8(0.6)$ \\
\hline$\geq 2.6-\leq 3.2$ & $30(8)$ & $-0.6(0.9)$ & $59(17)$ & $-0.6(0.6)$ & $66(19)$ & $-0.5(0.5)$ & $155(14)$ & $-0.6(0.6)$ \\
\hline$>3.2-<5.1$ & $154(41)$ & $-0.4(0.5)$ & $149(42)$ & $-0.5(0.5)$ & $149(42)$ & $-0.4(0.6)$ & $450(38)$ & $-0.4(0.5)$ \\
\hline$>5.1$ & $168(45)$ & $-0.1(0.5)$ & $61(17)$ & $-0.3(0.5)$ & $30(8)$ & $.0 .2(0.6)$ & $259(24)$ & $-0.2(0.5)$ \\
\hline \multicolumn{9}{|c|}{ X-ray progression ( $\leq 0$ cutoff) } \\
\hline No & $154(39)$ & $-0.3(0.5)$ & $191(48)^{\dagger}$ & $-0.5(0.6)$ & $222(56)^{1}$ & $.0 .6(0.6)$ & $550(46)$ & $-0.5(0.6)$ \\
\hline Yes & $244(61)$ & $-0.3(0.6)$ & $209(52)$ & $-0.6(0.5)$ & $177(44)$ & $-0.5(0.6)$ & $555(46)$ & $-0.4(0.6)$ \\
\hline \multicolumn{9}{|c|}{ X-ray progression ( $\$ 0.5$ cutoff) } \\
\hline No & $172(43)$ & $-0.4(0.5)$ & $219(55)^{1}$ & $-0.5(0.5)$ & $257(64)^{7}$ & $-0.6(0.6)$ & 648 (54) & $-0.5(0.6)$ \\
\hline Yes & 226 (57) & $-0.2(0.6)$ & $181(45)$ & $-0.6(0.5)$ & $142(36)$ & $-0.4(0.6)$ & $549(46)$ & $-0.4(0.6)$ \\
\hline
\end{tabular}

